\title{
Limb lengthening in Africa: tibial lengthening indicated for limb length discrepancy and postosteomyelitis pseudarthrosis
}

This article was published in the following Dove Press journal:

Orthopedic Research and Reviews

6 May 2014

Number of times this article has been viewed

\author{
Farikou Ibrahima ${ }^{1,2}$ \\ Pius Fokam ${ }^{2}$ \\ Félicien Faustin \\ Mouafo Tambo' \\ 'Department of Surgery and \\ Specialties, Faculty of Medicine and \\ Biomedical Sciences, University of \\ Yaoundé I, Yaoundé, 'Department of \\ Surgery, Douala General Hospital, \\ Douala, Cameroon
}

Correspondence: Farikou Ibrahima Department of Surgery and Specialities, Faculty of Medicine and Biomedical Sciences, University of Yaoundé I, Cameroon. P.O. Box I364,

Yaoundé, Cameroon

Tel +23799870267

Fax $+2372231 \quad 1224$

Email ifarikou@hotmail.com
Background: We present a case of lengthening of a tibia to treat postosteomyelitis pseudarthrosis and limb length discrepancy by the Ilizarov device.

Objective: The objective was to treat the pseudarthrosis and correct the consequent limb length discrepancy of $50 \mathrm{~mm}$.

Materials and methods: The patient was a 5-year-old boy. Osteotomy of the tibia, excision of fibrosis, and decortications were carried out. After a latency period of 5 days, the lengthening started at a rate of $1 \mathrm{~mm}$ per day.

Results: The pseudarthrosis healed and the gained correction was $21.73 \%$. The index consolidation was 49 days/cm. Minor complications were reported.

Discussion: Osteomyelitis of long bones is a common poverty-related disease in Africa. The disease usually is diagnosed at an advanced stage with complications. In these conditions, treatment is much more difficult. Most surgical procedures treating this condition use the Ilizarov device. The most common reported surgical complications are refractures and recurrence of infection.

Conclusion: This technique should be popularized in countries with limited resources because it would be an attractive alternative to the amputations that are sometimes performed.

Keywords: Limb length discrepancy (LLD), bone gap, Ilizarov device

\section{Introduction}

Limb lengthening has aroused great enthusiasm throughout the West in recent years. Paradoxically, in Africa, where the indications for limb lengthening are numerous (congenital or acquired abnormalities), this practice is not widespread, as evidenced by the scarcity of African literature on the subject. ${ }^{1-3}$

We present our initial experience of lengthening a tibia by the Ilizarov device indicated for posthematogenous osteomyelitis pseudarthrosis, in which limb length discrepancy is notoriously difficult to treat. The aim was twofold: to treat pseudarthrosis and correct the associated limb length discrepancy. Informed consent for publication of this case was given by the patient and his parents.

\section{Case report}

A 5-year-old boy presented with posthematogenous osteomyelitis and pseudarthrosis of the proximal tibia, with a leg length discrepancy of $50 \mathrm{~mm}$ after he underwent three unsuccessful surgeries done elsewhere (Figures 1 and 2). The history of the disease revealed that the child initially presented with fever and chills. He was then treated for malaria for a few days, as it is common in endemic areas. Given the persistence 


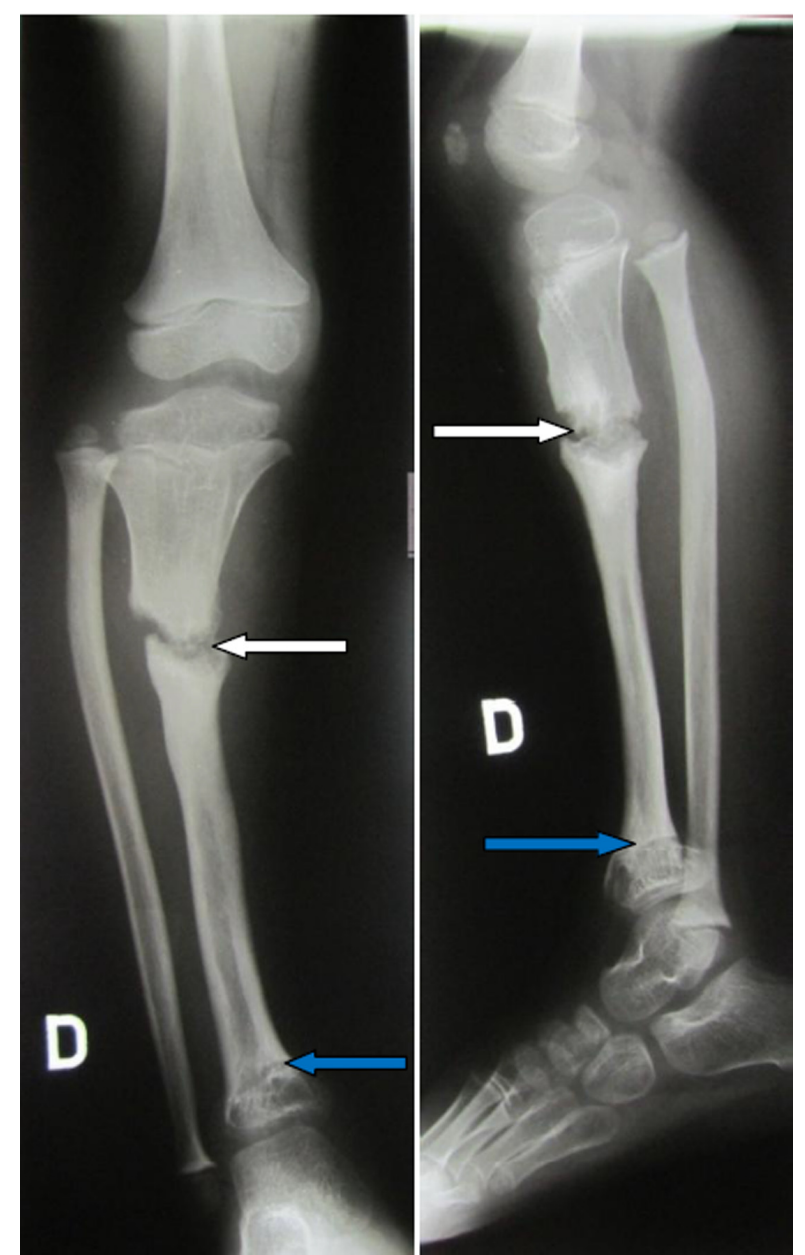

Figure I A 5-year-old child with pseudarthrosis of the proximal tibia previously operated on three times for hematogenous osteomyelitis (white arrows) and early epiphysiodesis (blue arrows).

of fever and the appearance of a painful swelling located at the proximal tibial metaphysis, accompanied by functional impairment, an X-ray of the leg revealed a subperiosteal abscess. Drainage of the abscess was then performed. The osteomyelitis which started at the metaphysis had evolved to a pandiaphyseal extension, thereby requiring an extensive approach up the distal metaphysis. It was probably during previous interventions that the distal growth plate was damaged, leading to early epiphysiodesis which in turn worsened the limb length discrepancy (Figure 1). However, there was no active infection at the time of the present surgery.

The surgery consisted initially of the application of the circular Ilizarov external fixator (Asco, New Delhi, India), which was made of two proximal rings and one distal ring (Figure 3). A thorough excision of fibrosis and freshening of the bone edges (decortications) at the site of the pseudarthrosis were carried out. A subperiosteal mid-diaphyseal approach was performed with a thin osteotomy chisel using the conventional technique described by Ilizarov. This was

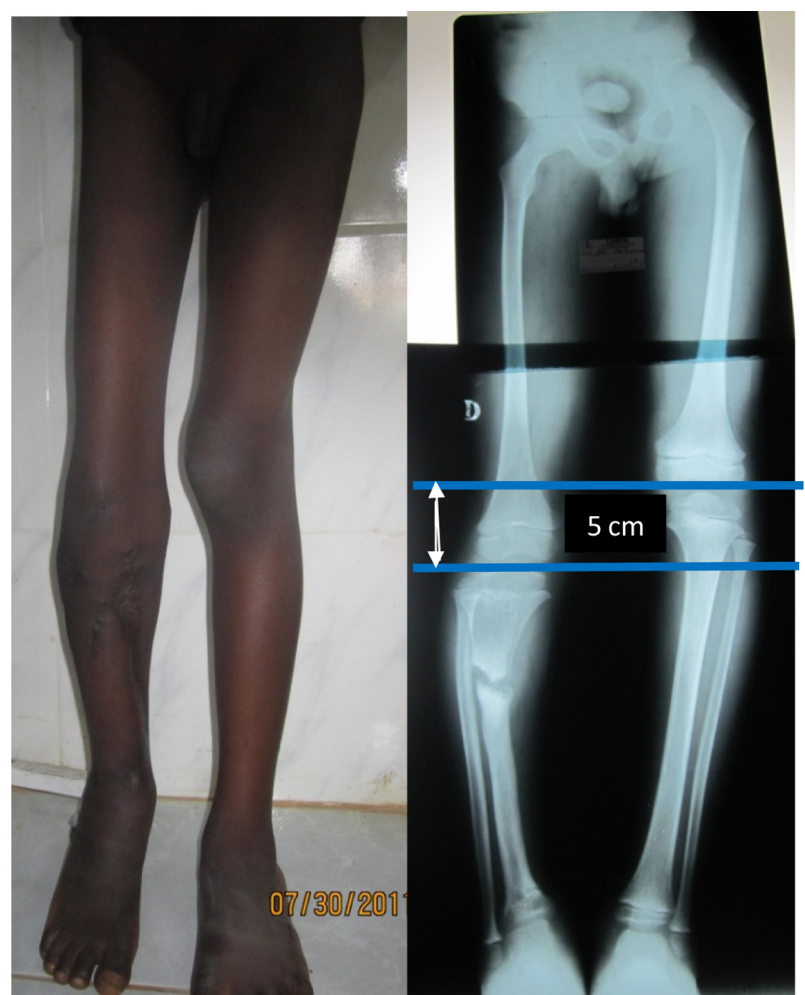

Figure 2 Same child with a consequent limb length discrepancy of $50 \mathrm{~mm}$ and proximal tibia pseudarthrosis.

done while avoiding roughening and shearing of the bone edges. At the end of the surgery, the periosteum was carefully sutured. The closure was made in layers without a drain.

After a latency period of 5 days, lengthening was performed at a rate of $1 \mathrm{~mm}$ per day $(0.5 \mathrm{~mm}$ in the morning and $0.5 \mathrm{~mm}$ in the evening) for about 50 days (Figure 3). An anti-foot drop device was applied immediately after surgery to prevent equinus deformity of the foot. Early physiotherapy was prescribed, and the boy was monitored regularly to prevent a flexion contracture or stiff knee.

We encountered two pin tract infections which were managed successfully by a short-term broad spectrum antibiotic (oxacillin $250 \mathrm{mg}$ twice a day for 15 days) and intensive dressing and nursing care.

The lengthening was stopped after the limb discrepancy was corrected and the site of the pseudarthrosis consolidated. The Ilizarov external fixator was left in place until the corticalization of the regenerate bone was achieved. Regular clinical and radiological controls were done to allow us to keep track of the progress of the lengthening and consolidation of the regenerate bone. The Ilizarov fixator was then removed and replaced by a long-leg synthetic cast for an additional 6 weeks to prevent early fracture. The consolidation of the regenerate bone was achieved after 245 

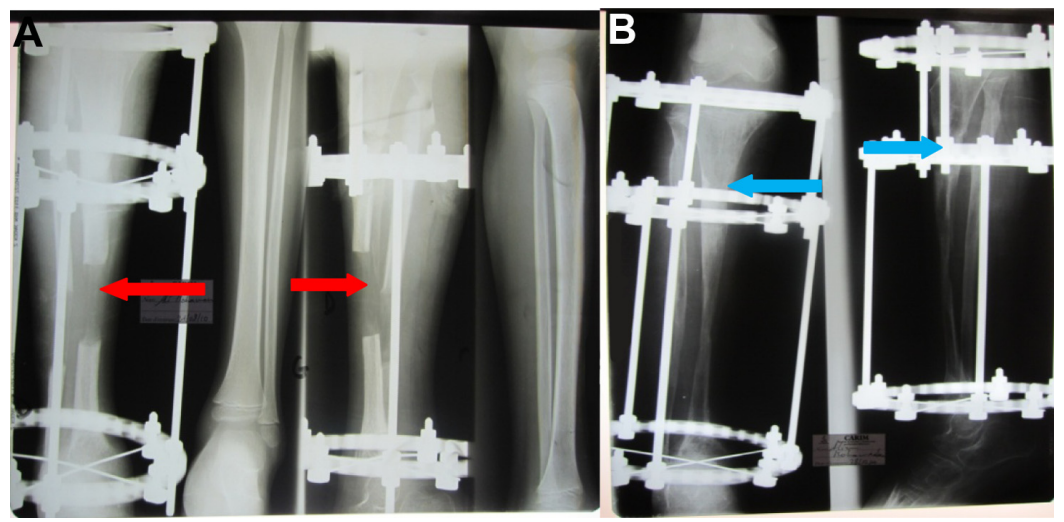

Figure 3 The mounted fixator device in place at the end of lengthening period: two proximal rings and one distal ring with a midshaft distracted osteotomy and regenerate bone (A, red arrows). Compression with progressive disappearance of the site of the pseudarthrosis (B, blue arrows).

days. The index consolidation of De Bastiani was 49 days/ $\mathrm{cm}$. The gain correction of leg length was $21.73 \%$.

The last radiological control on Day 1,187 (3 years, 3 months post-treatment) showed that consolidation of the pseudarthrosis was perfectly achieved, and that the diameter of the regenerate bone represented $76.8 \%$ of the diameter of the healthy contralateral tibia (Figure 4). The overall cost of this intervention was estimated at US\$1,610.98 $(1,171.11$ Euros). The boy, now 8 years old, shows no features of fracture or recurrence of infection (Figure 5).

\section{Discussion}

Osteomyelitis is a relatively common condition in Africa because it is related to poverty and its consequences, including malnutrition and overcrowding. ${ }^{4}$ Management of osteomyelitis,

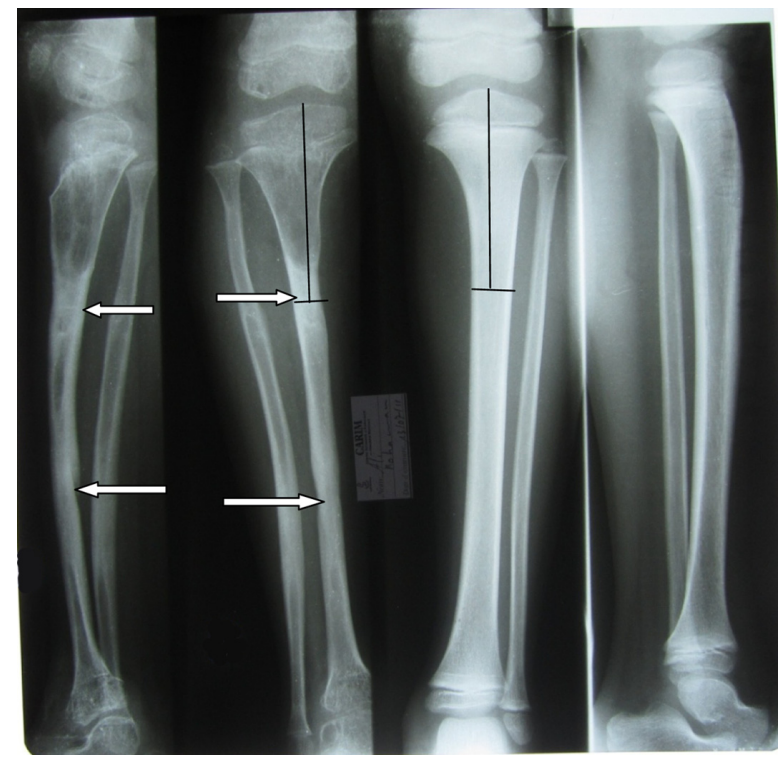

Figure 4 Appearance after removal of the llizarov external fixator and plaster: consolidation of the site of the pseudarthrosis and regenerate bone (white arrows) with an equivalence of $76.8 \%$ of the measured diameter of the contralateral healthy tibia at the same level. seen most often at the stage of chronicity and associated with local endemics (tuberculosis, AIDS, and sickle cell disease), is difficult. ${ }^{5}$ This case report presented nonunion of the tibia plus a lower limb length discrepancy due to an early epiphysiodesis, which was itself due to an alteration of the distal growth plate of the same tibia after iterative surgery. The treatment of pseudarthrosis in this case, despite its location in a fertile metaphyseal area and in inactive infectious focus, is not easy. In fact, the boy was operated upon three times in two different hospitals without success.

Our aim was two-fold: to treat pseudarthrosis and to correct the inequality of the shortened lower extremity by transporting a segment of the tibia using the Ilizarov technique. Several methods of treatment, from intramedullary nailing to vascularized fibular graft, have been used to treat congenital or

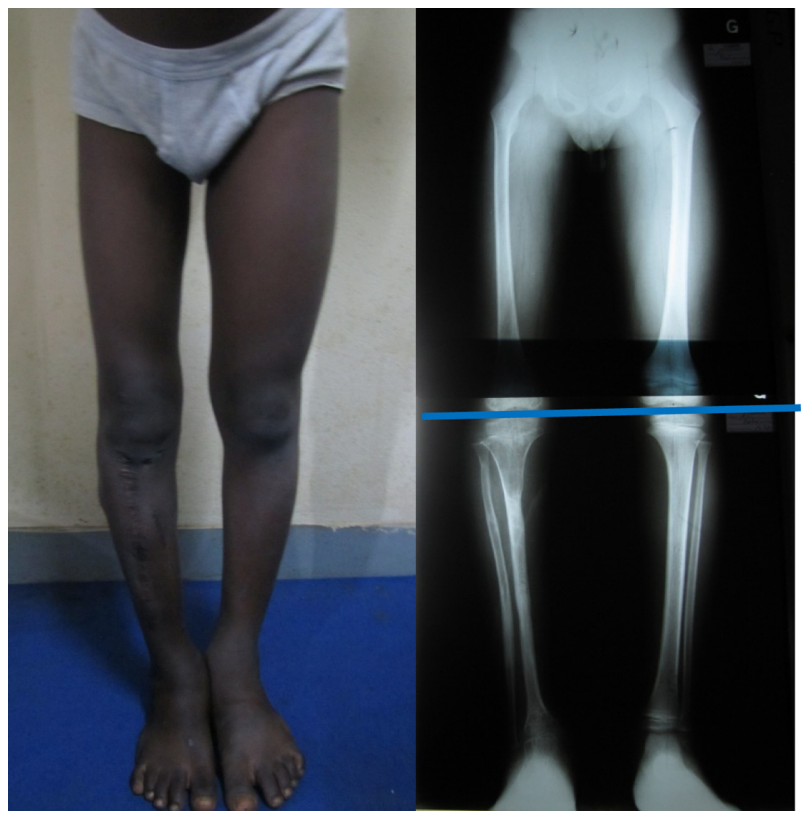

Figure 5 Final result: satisfactory combined treatment of pseudarthrosis and leg length discrepancy. 
acquired pseudarthrosis, with varying success. The vascularized fibular graft, often used in wealthy countries ${ }^{6}$ and requiring microsurgical anastomoses, is not always feasible in countries with limited resources. The use of external fixation alone or combined with intramedullary nailing is favored by several authors. ${ }^{4,7,8}$ The most common complications are paralysis of the common peroneal nerve, refracture, and residual shortening. ${ }^{4}$ The combined methods also tend to result in a higher rate of reinfection. ${ }^{4}$

In addition to treating pseudarthrosis, the Ilizarov external fixator offers the advantage of allowing the correction of abnormalities associated with this disease (angular deformities, limb length inequality). The additional immobilization by synthetic cast in this case permitted a solid regenerate bone, which was estimated to be $76.8 \%$ of the diameter of the contralateral tibia, and a healing index of 49 days/cm, comparable to those reported by Kucukkaya et $\mathrm{al}^{9}(52.3$ days $/ \mathrm{cm})$ and Eralp et $\mathrm{al}^{8}$ (40.09 days/cm). We had no refracture of regenerate, in contrast to that reported by Paley et al, ${ }^{10}$ who had five cases of refractures in a series of 16 cases of congenital pseudarthrosis, or El-Rosasy, ${ }^{4}$ who reported one refracture in 14 children treated for postosteomyelitis pseudarthrosis. The essential predisposing factor to the refractures reported by these authors is the fragility of the bones due to old pin tracts. Gualdrini et $\mathrm{al}^{11}$ also demonstrated the harmful effect of cigarette smoke on the period of consolidation in smokers. This period of consolidation is shortened by up to 33\% among nonsmokers in a series of 31 patients of both sexes treated for septic pseudarthrosis by the Ilizarov technique. ${ }^{11}$

The additional immobilization of the leg by a long-leg cast can protect the regenerate bone and avoid early refracture. The proximal fertile site of the pseudarthrosis contributes to heal the tibia without major complications.

\section{Conclusion}

The effectiveness of the Ilizarov technique in the treatment of congenital or acquired pseudarthrosis with minor complications is well established. This technique should be popularized in Africa and the indications extended to loss of substance of traumatic origin, because it would be an attractive alternative to the many amputations performed, sometimes as a last resort. To prevent further residual limb length inequality recurrences, it is judicious to later plan and carry out the treatment of the early epiphysiodesis of the distal growth plate by distraction.

\section{Disclosure}

The authors declare no conflicts of interest in this work.

\section{References}

1. Eze KC, Akhigbe AO, Awosanya GO. Fibular hemimelia: a case report. Niger J Clin Pract. 2007;10(3):259-261.

2. Ibrahima F, Mouafo Tambo FF, Ngo Nonga B, Bahebeck J, Sosso MA. Notre expérience initiale d'allongement des membres inférieurs en milieu africain. Rev Afr Chir Spéc. 2010;4(8):28-31. French.

3. Ibrahima F, Motah M, Ngo Nonga B, et al. Hémimélie fibulaire de type II. Cas clinique traité par Ilizarov et revue de la littérature. Méd Afr Noire. 2012;59(1):15-19. French.

4. El-Rosasy MA. Ilizarov treatment for pseudarthrosis of the tibia due to haematogenous osteomyelitis. J Pediatr Orthop B. 2013;22(3): 200-206.

5. Ibrahima F, Pisoh-Tagnyin C, Abolo-Mbenti L, Sosso MA, Eimo Malonga E. Bilan des infections ostéoarticulaires à Yaoundé. Expérience du Centre National de Réhabilitation des Handicapés à propos de 20 cas opérés. Méd Afr Noire. 2005;52(12):701-706. French.

6. Minami A, Kasashima T, Iwasaki N, Kato H, Kaneda K. Vascularised fibular grafts. An experience of 102 patients. J Bone Joint Surg Br. 2000;82(7):1022-1025.

7. Zehi K, Karray S, Fathallah M, et al. [Use of Ilizarov fixator in the treatment of post-osteomyelitis pseudoarthroses in children]. Rev Chir Orthop Reparatrice Appar Mot. 1999;85(3):231-237. French.

8. Eralp L, Kocaoğlu M, Polat G, Baş A, Dirican A, Azam ME. A comparison of external fixation alone or combined with intramedullary nailing in the treatment of segmental tibial defects. Acta Orthop Belg. 2012;78(5):652-659.

9. Kucukkaya M, Kabukcuoglu Y, Tezer M, Kuzgun U. Management of childhood chronic tibial osteomyelitis with the Ilizarov method. J Pediatr Orthop. 2002;22(5):632-637.

10. Paley D, Catagni M, Argnani F, Prevot J, Bell D, Armstrong P. Treatment of congenital pseudoarthrosis of the tibia using the Ilizarov technique. Clin Orthop Relat Res. 1992;280:81-93.

11. Gualdrini GD, Zati A, Degli Esposti S. The effects of cigarette smoke on the progression of septic pseudarthrosis of the tibia treated by Ilizarov external fixator. Chir Organi Mov. 1996;81(4):395-400.
Orthopedic Research and Reviews

\section{Publish your work in this journal}

Orthopedic Research and Reviews is an international, peer-reviewed, open access journal focusing on the patho-physiology of the musculoskeletal system, trauma, surgery and other corrective interventions to restore mobility and function. Advances in new technologies, materials, techniques and pharmacological agents are particularly welcome. The journal welcomes

Submit your manuscript here: http://www.dovepress.com/orthopedic-research-and-reviews-journa

\section{Dovepress}

original research, clinical studies, reviews \& evaluations, expert opinion and commentary, case reports and extended reports. The manuscript management system is completely online and includes a very quick and fair peer-review system, which is all easy to use. Visit http://www.dovepress. com/testimonials.php to read real quotes from published authors. 